\title{
Papers
}

\section{Principal component analysis (PCA) to rank countries on their readiness for e-tail}

Received (in revised form): 24 December 2007

\section{Soumitra Sharma}

completed his Bachelor of Technology (BTech) in Chemical Engineering from the Institute of Technology, Banaras Hindu University. He published papers in several technical areas such as biofuels, wastewater treatment and nanotechnology, during his engineering course. His current areas of expertise include consumer goods, retail and e-Government. In the latter, Soumitra has worked on projects related to 'public-private partnership in e-Government' in recent months. He already has two international publications in the area of e-Government to his credit. Recently, he was among the few professionals globally, to be extended a personal invitation by the John F. Kennedy School of Government at Harvard University, to attend the executive programme 'Successful Cross-Boundary Transformation: The Role of Executive Sponsors', in June 2007.

\begin{abstract}
e-Tail, or internet-based retailing, has emerged as an innovative channel for retailers to reach target consumers in the comfort of their homes. e-Tailing has exhibited an upward trend across the world in recent years, although it is more prevalent in certain regions such as Europe and North America. With varying levels of internet penetration, telecom infrastructure, the business and legal environment, e-tailing is at varying stages of maturity in countries across the globe. In order to objectively compare the actual preparedness of various countries to exploit their potential for e-tail, an analytical model was built by using principal component analysis. This model returns a numeric value, coined as the $e$-Tail Readiness Index. A set of countries were subsequently ranked on the basis of this index. As expected, while the more developed countries of Europe and North America occupied the top slots, the emerging economies of eastern Europe and Latin America occupied the middle slots. Surprisingly, India and China figured right at the bottom of the heap.
\end{abstract}

Soumitra Sharma

Consumer Goods and Retail Institute of Technology Banaras Hindu University D-27, First Floor, Saket New Delhi-110017, India Tel: +919810877422 Fax: + 911202522592 E-mail: soumitrasharma555@ yahoo.co.in

\section{Keywords:}

e-tail, principal component analysis, e-tail readiness index

Journal of Retail and Leisure Property (2008) 7, 87-94. doi:10.1057/rlp.2008.1; published online 5 March 2008

\section{INTRODUCTION TO e-TAIL}

e-Retailing, or e-Tailing, has emerged as a great opportunity in the world of business. As compared to the traditional brick-and-mortar retailing, 
e-tailing seems to be a more attractive alternative. e-Tailing is a relatively new concept as it has made its presence felt only a few years ago. It can be better explained as internet retailing, wherein various technologies and media are combined to sell products online. e-Tail has quickly grabbed the attention of many entrepreneurs worldwide. Thanks to the growing popularity of internet all over the world, people have started shopping online in a big way.

\section{Differences between retail and e-tail}

Anything involving a direct sale to a consumer at any point of time can be termed as retailing. This retailing can be done in a shopping mall, a departmental store or in a basic mom-and-pop store. This imposes geographical constraints on the retailer. On the other hand, an e-tailer has global reach due to the internet acting as a medium of retail.

A conventional retailer has to identify a good location for his operations, and attract consumers using advertising and promotional schemes. An e-tailer, however, has to attract consumers 'virtually' to his site and offer services. Thus, while the target consumer remains the same in both forms of retail, the business model is entirely different. In conventional retailing, as much as 50 per cent of the initial investment could go towards acquiring real estate. This is not the case with e-tail.

Consumer retention is also very different in both the scenarios.

Retaining a consumer on the internet is not simple as his/her behaviour is hard to predict. While conventional retailers succeed in forming a bond with the consumer through personalised attention via face-to-face interaction, convenient geographical location etc such loyalty is difficult to obtain in virtual space. A consumer may simply switch from one shopping website to another in case it offers a better deal.

\section{Current trends in e-tail}

e-Tail is most prevalent in Europe and North America. Specifically, Germany, Austria and the UK come at the top, with almost 95 per cent internet users shopping online in each country. South Korea and Taiwan come at the top in Asia-Pacific, with close to 90 per cent of all internet users indulging in e-tail (ACNielsen News Release, 2005). On the whole, e-tailing is exhibiting an upward trend across the world, with the emerging economies showing more vibrant growth as compared to the developed countries.

Consumer behaviour depends heavily on both the buying channel (conventional retail vs the internet) and the category of products being bought. The most popular product categories purchased online across the world include books, followed by videos/DVDs/games, airline tickets/ reservations and clothing/accessories/shoes (ACNielsen News Release, 2005). Chinese and South Koreans are one of the biggest buyers of books on the internet, and therefore, e-tailers should make sure that their websites support the corresponding native languages. Japan, on the other hand, is a huge opportunity for online booksellers and grocery sites.

Airline tickets/reservations are the most prevalent in Malaysia, New Zealand, Singapore and Australia. Tours and hotel reservations are the most prevalent in Finland and Spain (ACNielsen News Release, 2005). 
Online purchase of videos/DVDs/games is most preferred in UK and France. On the other hand, electronics are the most preferred category for online purchase in Latin America. Overall, credit cards are the most preferred mode of online payment across the world. In most regions, including North America and Latin America, credit cards are followed by PayPal in popularity.

\section{e-TAIL READINESS INDEX}

\section{Introduction}

With varying levels of internet penetration, telecom infrastructure, the business and legal environment, e-tailing is at varying stages of maturity in countries across the globe. Although e-tail's potential to capture a significant chunk of the traditional retail market has now been widely accepted, especially in developed countries, it is interesting to compare the actual preparedness of various countries to exploit this potential. In order to do so objectively, an analytical model was built that returns a numeric value for the set of countries under study. This numeric value has been coined as the $e$-Tail Readiness Index, and serves as a yardstick to measure the readiness of a country's e-tailing market to take-off. Owing to constraints of data availability, this index was calculated for a set of 30 countries, with data for all parameters collected for the year 2005.

\section{Constituent parameters}

The $e$-Tail Readiness Index has been defined as a composite index of seven individual parameters. These include:

- Number of personal computer owners per 1,000 people

- Number of internet users per 100 people

- Number of telephone connections (mobile + fixed) per 100 people

- Per capita GDP

- Business and Regulatory Environment Index

- Consumer and Business Adoption Index

- Supporting E-services Index

The first three parameters reflect the status of ICT (information and communication technology) infrastructure in the country (data taken from EIU) database). The fourth parameter, the per capita GDP of the country, is a proxy for the average buying power of the citizens in the country.

The 'Business and Regulatory Environment Index', is a measure of the general business climate of the country, along with the country's legal and regulatory framework from the perspective of internet usage (EIU White Paper, 2005). It is calculated as the mean of the 'business environment' score and the 'legal and policy environment' score, developed by the Economist Intelligence Unit.

The 'Consumer and Business Adoption Index' reflects the citizen's acceptance of internet-based services (EIU White Paper, 2005). The values for this parameter have been directly obtained from the scores developed by the EIU. 
The 'Supporting E-services Index' is a measure of various ancillary services present to support internet-based businesses (EIU White Paper, 2005). From the perspective of e-tailing, these could include web designers, ISP infrastructure providers, software professionals and IT consulting services. The values for this parameter too have been directly obtained from the scores developed by the EIU.

The weight assigned to each parameter was arrived at using the principal component analysis (PCA) method. This is discussed in the next section.

\section{PRINCIPAL COMPONENT ANALYSIS}

The $e$-Tail Readiness Index $\left(C_{j}\right)$ was developed as a linear composite index of the previously discussed seven parameters. This is represented in equation (1).

$$
C_{j}=W_{1} x_{1 j}+W_{2} x_{2 j}+W_{3} x_{3 j}+W_{4} x_{4 j}+W_{5} x_{5 j}+W_{6} x_{6 j}+W_{7} x_{7 j}
$$

where $C_{j}$ refers to the $e$-Tail Readiness Index for the $j$ th country, $x_{i j}$ refers to the standardised value of the $i$ th parameter for the $j$ th country and $W_{i}$ is the corresponding weight. Instead of subjectively assigning weights to each parameter, the PCA method was adopted to calculate weights objectively.

This PCA method is based on the principle that "when different characteristics are observed about a set of events, the characteristic with more variation explains more of the variation in the dependent variable compared to a variable with lesser variation in it' (Annexure on Principal Component Analysis - Government of India, 2003). This technique assigns weights in such a way that they maximise the 'sum of the squares of correlation' of the indicators with the composite index. The various steps involved in the process are discussed in detail below.

\section{Standardisation of data}

As all short-listed parameters are measured in different units, they are not directly additive. Therefore, it is necessary to convert them into standard comparable units, to eliminate any bias of the initial scale. Each data point was standardised according to equation (2).

$$
x_{i j}=\left(X_{i j}-X_{m}\right) / \sigma
$$

$$
i=1,2 \ldots 7 \text { (Parameter No.) }
$$

$j=1,2 \ldots 30$ (Country No.)

$X_{i j}$ is the original value of the $i$ th parameter for the $j$ th country, $X_{m}$ is the mean, and $\sigma$ is the standard deviation of the series formed by values of the $i$ th parameter for all 30 countries.

\section{Construction of a correlation matrix}

A correlation matrix was constructed, as given in Table 1, by calculating the simple correlation coefficients of each corresponding 
pair of indicators. The complete matrix was constructed via the following steps:

Step1: The simple correlation coefficients of each corresponding pair of indicators were calculated. For example, $r_{x 1 \times 2}$ is the correlation coefficient of two arrays. The first array is the series of all 30 values for the parameter $x_{1}$, and the second is the similar series for $x_{2}$. The elements of the diagonal of the matrix would be unity as they are self-correlated $\left(r_{x i x i}=1\right)$. The matrix is also symmetrical as the elements of each row are identical to the elements of the corresponding column $\left(r_{x i x j}=r_{x j x i}\right)$.

Step 2: The 'column-sum' of all coefficients in each particular column was calculated. Seven such 'column-sums' were obtained.

Step 3: The above seven column-sums were added to obtain a 'grand column-sum' denoted by $S$.

\section{Calculation of weights}

The weight $W_{1}$ (for parameter $x_{1}$ ) was calculated according to equation (3).

$$
W_{1}=\left(\sum r_{x i x}\right) / \sqrt{ } S
$$

Similarly, all weights $W_{2} \ldots W_{7}$ were calculated. These are given in Table 2.

These weights were put in equation (1) to calculate the $e$-Tail Readiness Index $\left(C_{j}\right)$ for each of the 30 countries. The final composite index values for the countries were normalised to represent them on a scale of $1-10$.

Table I: Correlation matrix

\begin{tabular}{|c|c|c|c|c|c|c|c|}
\hline & $x_{1}$ & $x_{2}$ & $x_{3}$ & $\mathbf{x}_{4}$ & $x_{5}$ & $x_{6}$ & $x_{7}$ \\
\hline$x_{1}$ & $r_{x|x|}$ & $r_{x \mid \times 2}$ & - & - & - & - & $r_{x \mid x 7}$ \\
\hline$x_{2}$ & - & - & - & - & - & - & - \\
\hline$x_{3}$ & - & - & - & - & - & - & - \\
\hline$x_{4}$ & - & - & - & - & - & - & - \\
\hline$x_{5}$ & - & - & - & - & - & - & - \\
\hline$x_{6}$ & - & - & - & - & - & - & - \\
\hline$x_{7}$ & $r_{x 7 \times 1}$ & & - & - & - & - & $r_{x 7 \times 7}$ \\
\hline Column sum of coefficients & $\Sigma r_{\text {xix }}(i=1 \ldots 7)$ & $\Sigma r_{x i x 2}(i=1 \ldots 7)$ & - & - & - & - & $\Sigma r_{x i x}(i=1 \ldots 7)$ \\
\hline Grand column sum & $S=\Sigma\left(\Sigma r_{x i x \mid}+\Sigma r\right.$ & $\left.+\sum r_{x i x}\right)$ & & & & & \\
\hline
\end{tabular}

Table 2: Weights obtained from PCA

\begin{tabular}{llllllll}
\hline Parameters $\rightarrow$ & $\begin{array}{l}\text { PC owners } \\
\text { per I,000 } \\
\text { people }\end{array}$ & $\begin{array}{l}\text { Internet } \\
\text { users per } \\
\text { 100 people }\end{array}$ & $\begin{array}{l}\text { Number of mobile and } \\
\text { fixed line connections } \\
\text { per 100 people }\end{array}$ & $\begin{array}{l}\text { Per capita } \\
\text { GDP }\end{array}$ & $\begin{array}{l}\text { Business and } \\
\text { regulatory } \\
\text { environment index }\end{array}$ & $\begin{array}{l}\text { Consumer } \\
\text { and business } \\
\text { adoption index }\end{array}$ & $\begin{array}{l}\text { Supporting } \\
\text { e-services } \\
\text { index }\end{array}$ \\
\hline Weight & 0.94 & 0.95 & 0.91 & 0.95 & 0.96 & 0.92 & 0.96 \\
\hline
\end{tabular}




\section{RESULTS AND DISCUSSION}

Figure 1 represents the results of the analytical model developed earlier.

As depicted in the bar graph, the United States leads the pack, scoring 9.18 (on a scale of 10), followed by the United Kingdom, Hong Kong, Australia and Canada. It is interesting to note that even though the US lags behind countries such as the UK and Germany, in terms of internet penetration and telecom density, it scored the highest in the composite index. This was primarily due to its high scores in the Consumer and Business Adoption Index, Supporting E-services Index and per capita GDP. The Supporting E-services Index for the US was one of the highest among all 30 countries, thus reflecting the presence of excellent ITsupport services. On the other hand, Canada ranked fourth on the index, despite excellent values of ICT infrastructure parameters. This was due to a low Consumer and Business Adoption Index. This highlights that, despite excellent ICT penetration, Canadians are not psychologically ready as yet, to utilise these ICT channels for online purchases. Rather, they are more likely to consider the web as a marketing, customer service and pre-purchase research tool. It is validated by the fact that only 17 per cent of Canadians made online purchases in 2001, as

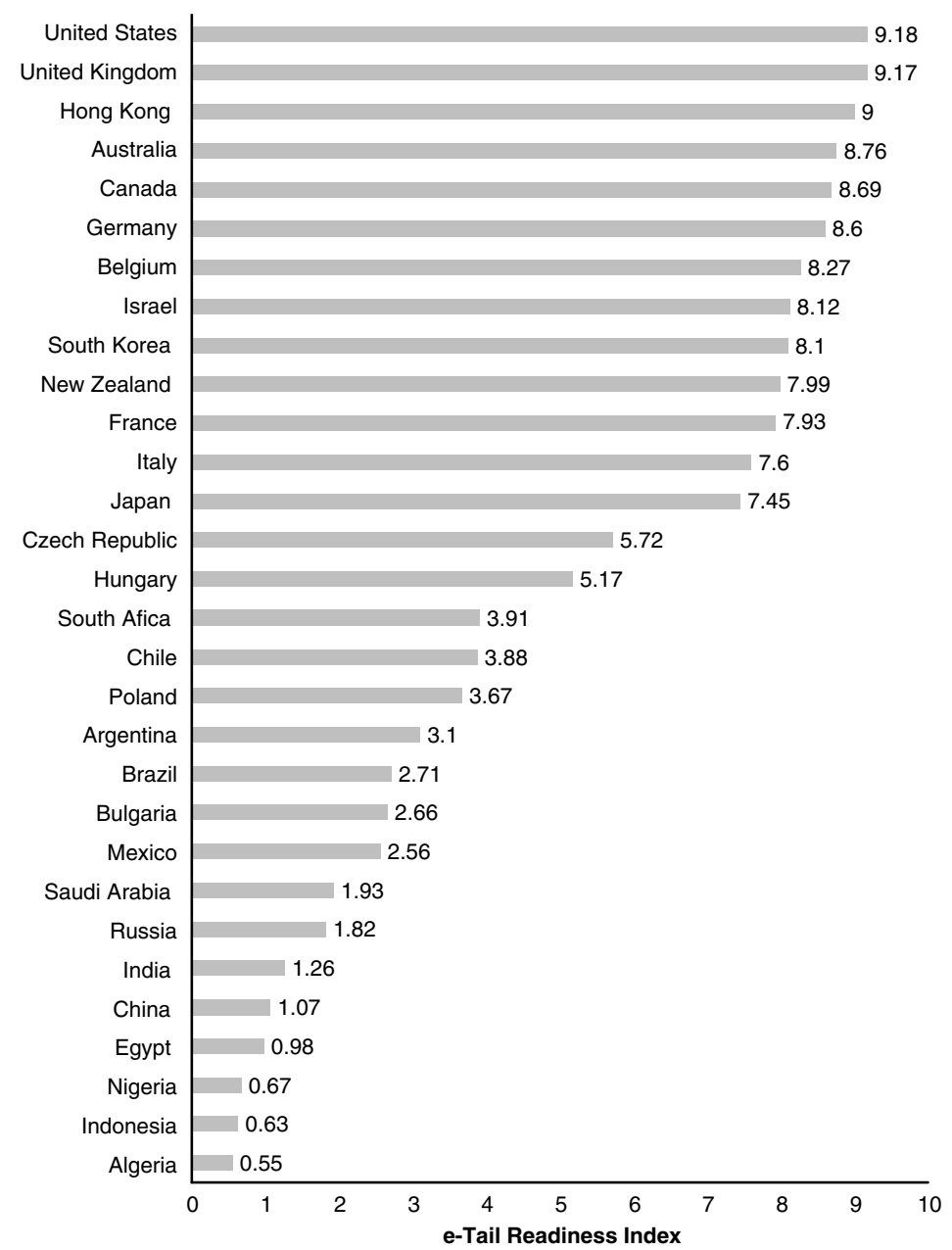

Figure I: Comparison of e-tail readiness across countries 
compared to 27 per cent of Americans (Canadian IT Law Newsletter, 2002).

Unlike the US, the online retail market in western Europe is quite heterogeneous, consisting of local markets at different levels of development. Internet penetration varies significantly across Europe, with the Nordic countries at the highest end of the spectrum, and countries such as Italy, Spain, France and Portugal at the lower end. Similarly, online purchasing habits vary considerably across the region, with the UK, France and Italy being heavy users of credit cards, while Germany and the Nordic countries are more reluctant to make credit card payments. In Germany and the Nordics, less than 20 per cent of online transactions are paid by credit cards, whereas the number stands at around 90 per cent for the UK. Against this backdrop, the UK was the only European country at par with the US in terms of e-tail readiness, scoring 9.17 on a scale of 10. Apart from the UK, Germany also scored well - a decent 8.6. France and Italy were down the list, and were ranked 11th and 12th, respectively.

The BRIC countries were part of the lowest ranked countries in the group. Brazil led the BRIC group, followed by Russia, India and finally China. Although Russia scored better than Brazil in ICT infrastructure parameters, it lagged behind considerably in the other three parameters. Same was the case with China and India, with China lagging behind India by a considerable margin in all parameters other than the ICT infrastructure-related ones.

\section{CONCLUSION}

As discussed in previous sections, the PCA is a handy mathematical tool to rank countries on their readiness for e-tail. The $e$-Tail Readiness Index developed earlier can be used by e-tailers to do a gap analysis of various countries, vis-à-vis benchmark countries that have the highest scores (such as the US and UK). The index can also be used as a barometer of a country's maturity with respect to e-tail, and the potential it holds for the future. While the more developed countries of Europe and North America occupied the top slots (as expected), it is the emerging economies of eastern Europe and Latin America that occupy the middle slots and will be of most interest to retailers. As indicated by the index, these markets are ripe enough for sustainable e-tail, but immature enough to exhibit bright growth prospects for the future. Surprisingly, the 'in-vogue' growth engines of the world, India and China, figure right at the bottom of the heap. Therefore, going strictly by numbers, both the global giants are still not viable enough for e-tailers. Although, strategically speaking, it could be a totally different story.

\section{Acknowledgements}

I acknowledge the role of Mr Manas Nanda, Business Analyst, for his valuable contribution to the development of the index.

\section{References}

ACNielsen News Release (2005). ACNielsen announces one-tenth of the world's population shopping online: 627 million people have, including 325 million in the last month, ACNielsen 
News Release. Retrieved from http://www2.acnielsen.com/news/20051019.shtmlon 22 December 2007.

Canadian IT Law association (2002). Canadian IT law newsletter, Canadian IT Law Association. Retrieved from http://www.it-can.ca/newsletters/040402.pdfon 22 December 2007.

Department of Information Technology, Ministry of Communications and Information Technology, Government of India (2003). Annexure on principal component analysis, Department of Information Technology, Ministry of Communications and Information Technology,

Government of India. Retrieved from http://www.mit.gov.in/download/ANNEX_242-254. PDFon 22 December 2007.

The Economist Intelligence Unit and the IBM Institute for Business Value (2005). The 2005 E-readiness rankings, The Economist Intelligence Unit and the IBM Institute for Business Value — White Paper. Retrieved from http://graphics.eiu.com/files/ad_pdfs/2005Ereadiness_ Ranking_WP.pdfon 22 December 2007.

The Economist Intelligence Unit (EIU) Database, http://www.eiu.com. 